\title{
Control of Body Temperature during Physical Exercise
}

\author{
Ricardo Luiz Damatto, ${ }^{1,2}$ Marcelo Diarcadia Mariano Cezar, ${ }^{1,2}$ Priscila Portugal dos Santos $^{2(0)}$ \\ Sociedade Cultural e Educacional de Itapeva - Educação Física, ${ }^{1}$ Itapeva, SP - Brazil \\ Universidade Estadual Paulista Júlio de Mesquita Filho Campus de Botucatu -Faculdade de Medicina, ${ }^{2}$ Botucatu, SP - Brazil \\ Short Editorial related to the article: Thermoregulation in Hypertensive Rats during Exercise: Effects of Physical Training
}

Physical exercise is currently recommended for health promotion and as a non-pharmacological treatment of cardiovascular diseases. Regular exercise results in improved body composition and physical capacity, as well as decreased insulin resistance and arterial hypertension, leading to ameliorated quality of life. ${ }^{1}$

During exercise, heat is a by-product of metabolism, which leads to increased body temperature. However, the human body needs to maintain a stable temperature, around $37^{\circ} \mathrm{C}$, using neural and cardiovascular mechanisms. The temperature-regulating center is found in the anterior hypothalamus. It receives information on the ambient temperature, through the skin thermoreceptors, and on the internal temperature, through the hypothalamic thermoreceptors. Thus, the hypothalamus promotes appropriate responses of heat generation or dissipation, which involve arteriovenous redistribution of blood. ${ }^{2}$ Therefore, individuals with cardiovascular comorbidities such as type II diabetes, hypercholesterolemia and arterial hypertension may present impairment of thermoregulation mechanisms. ${ }^{3}$

In order to study and evaluate hypertension, Spontaneously Hypertensive Rats (SHR) are commonly used as a model, since they resemble the condition found in humans. ${ }^{4,5}$ Therefore, the Gomes et al. ${ }^{6}$ used SHR rats

\section{Keywords}

Exercise; Rats; Rats, Inbred SHR/physiology; Body Temperature Regulation.

Mailing Address: Ricardo Luiz Damatto •

Sociedade Cultural e Educacional de Itapeva - Educação Física - Rod. Francisco Alves Negrão, 258 - km 285. Postal Code 18412-000, Itapeva, SP - Brazil E-mail: ridamatto@yahoo.com.br

DOI: $10.5935 / a b c .20190081$ to evaluate the effects of low-intensity physical exercise training on thermal balance.

After 12 weeks of exercise protocol, the Gomes et al. ${ }^{6}$ showed a reduction in blood pressure in trained SHR. In addition, trained SHR presented lower skin temperature than trained Wistar. This show an impaired heat dissipation in SHR. However, physical exercise did not influence the promotion of positive adaptations on thermoregulation. ${ }^{6}$

In humans, heat dissipation responses involve increased sweating, as the main mechanism, and cutaneous active vasodilation. ${ }^{2}$ Thermoregulatory responses in rats are different. Cutaneous vasodilation of the tail is the main mechanism of heat dissipation in this species, accounting for $40 \%$ of heat loss during exercise. ${ }^{7}$ This mechanism can be activated by central cholinergic stimulation via modulation of arterial baroreceptors by increasing the blood flow of the rat's tail. ${ }^{8,9}$ Additionally, vasodilation of the skin of the feet, the evaporation of saliva spread onto the body surface, the evaporation of water from the respiratory tract and even voluntary urination associated with urine spreading activity may also contribute to the total heat dissipation. ${ }^{10}$

Considering the relationship between the cardiovascular system and the regulation of body temperature, hypertension can affect the mechanisms of heat dissipation. In SHR rats, for example, decreased baroreceptor sensitivity, sympathetic hyperactivity, which leads to increased peripheral resistance, and endothelial dysfunction may impair cutaneous vasodilation of the tail and, consequently, heat dissipation. ${ }^{7,9}$

In fact, the Gomes et al. ${ }^{6}$ found lower skin temperature in trained SHR than in trained Wistar. This shows a lower heat dissipation in hypertensive animals during exercise. However, the author did not observe alterations in the internal temperature, heat dissipation threshold, sensitivity and cumulative heat normalized by the work. One possible explanation is that other mechanisms of heat dissipation, besides cutaneous vasodilation of the tail, may have been used by these animals. 


\section{References}

1. Pagan LU, Gomes MJ, Okoshi MP. Endothelial function and physical exercise. Arq Bras Cardiol. 2018;111(4):540-1.

2. Guyton AC, Hall EJ. Guyton and Hall Textbook of Medical Physiology. Philadelphia: Elsevier Saunders; 2015. P.911-9.

3. Schlader ZJ, Coleman GL, Sackett JR, Sarker S, Chapman CL, Hostler D, et al. Behavioral thermoregulation in older adults with cardiovascular comorbidities. Temperature (Austin). 2017;5(1):70-85.

4. Cezar MD, Damatto RL, Pagan LU, Lima AR, Martinez PF, Bonomo C, et al. Early spironolactone treatment attenuates heart failure development by improving myocardial function and reducing fibrosis in spontaneously hypertensive rats. Cell Physiol Biochem. 2015;36(4):1453-66.

5. Damatto RL, Lima ARR, Martinez PF, Cezar MDM, Okoshi K, Okoshi MP. Myocardial myostatin in spontaneously hypertensive rats with heart failure. Int J Cardiol. 2016 Jul 15;215:384-7.

6. Gomes LHLS, Drummond LR, Campos HO, Rezende LMT, CarneiroJúnior MA, Oliveira A, et al. Thermoregulation in Hypertensive Rats during Exercise: Effects of Physical Training. Arq Bras Cardiol. 2019; 112(5):534-542.

7. Campos HO, Leite LH, Drummond LR, Cunha DN, Coimbra CC, Natali AJ et al. Temperature control of hypertensive rats during moderate exercise in warm environment. J Sports Sci Med, 2014;201;13(3):695-701.

8. Pires W, Wanner SP, Lima MR, Oliveira BM, Guimarães JB, de Lima DC, et al. Sinoaortic denervation prevents enhanced heat loss induced by central cholinergic stimulation during physical exercise. Brain Res, 2010;1366(17)::120-8.

9. da Fonseca SF, Mendonça VA, Silva SB, Domingues TE, Melo DS, Martins J B, et al. Central cholinergic activation induces greater thermoregulatory and cardiovascular responses in spontaneously hypertensive than in normotensive rats. J Therm Biol. 2018 Oct;77:86-95.

10. Wanner SP, Prímola-Gomes TN, Pires W, Guimarães JB, Hudson AS Kunstetter AC, et al. Thermoregulatory responses in exercising rats: methodological aspects and relevance to human physiology. Temperature (Austin). 2015;2(4):457-75. 